\title{
Hypercalcaemia A portent of sarcoidosis in cystic fibrosis
}

"Jayakrishnan B., Saif M. Al-Mubaihsi, Masoud S. Kashoub, Jojy George

$$
\text { نذير للساركويد في الثيوم اللكيسم }
$$

جاياكريشنان بالاكريشنان ناير، سيف مصبح المبيحسي، مسعود سالم كشوب، جوجي جورج

ABSTRACT: The coexistence of cystic fibrosis (CF) and sarcoidosis is rare. We report a 22-year-old male cystic fibrosis patient who presented multiple times to the Sultan Qaboos University Hospital, Muscat, Oman, in 2013. He was diagnosed with non-parathyroid-related hypercalcaemia and anterior uveitis, while computed tomography revealed mediastinal and abdominal lymphadenopathy and mild hepatosplenomegaly. These findings, in addition to the presence of calciuria and a high angiotensin-converting enzyme (ACE) level, confirmed a clinical diagnosis of sarcoidosis. The patient responded well to treatment with oral prednisolone which, over the course of two years, resulted in the near-complete resolution of parenchymal nodular infiltrates, regression of hilar lymphadenopathy, resolution of hypercalcaemia and the normalisation of his ACE levels. Diagnosing pulmonary sarcoidosis in CF can be challenging as most adult patients already have extensive lung disease. Physicians should be aware that hypercalcaemia may be an early manifestation of sarcoidosis in such cases.

Keywords: Sarcoidosis; Cystic Fibrosis; Hypercalcemia; Case Report; Oman.

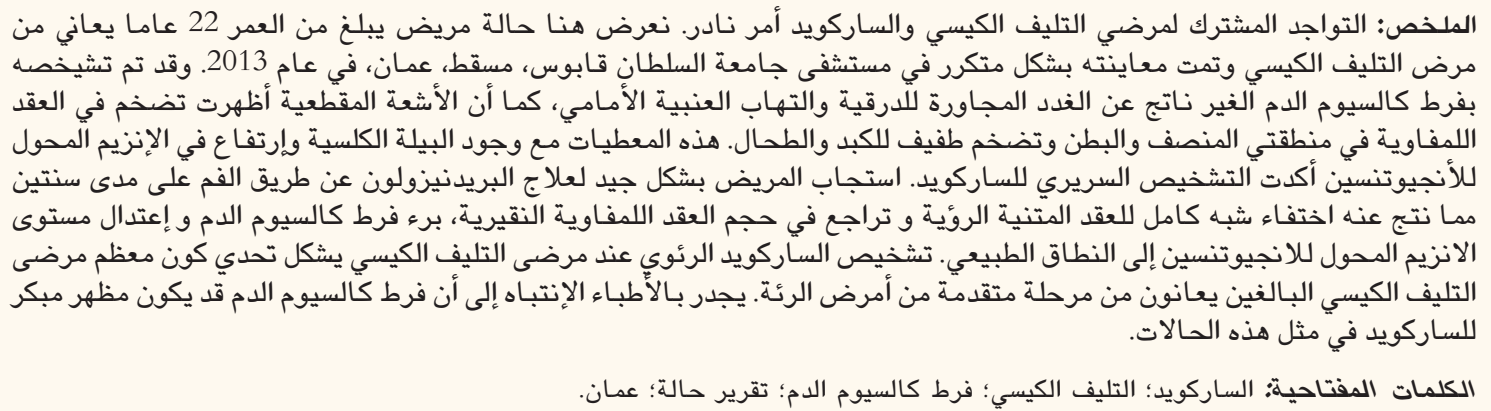

$\mathrm{S}$ ARCOIDOSIS IS A SYSTEMIC DISEASE CHARACTerised by the formation of immune granulomas in various organs - mainly the lungs and lymphatic system-usually resulting from an exaggerated reaction to unidentified antigens in susceptible individuals. ${ }^{1} \mathrm{On}$ the other hand, cystic fibrosis (CF) is an autosomal recessive multisystem disorder that affects several organs, including the lungs, pancreas, liver and intestine. ${ }^{2}$ The former disease has a prevalence of approximately 4.7-64 per 100,000 individuals per year worldwide, while the latter occurs in approximately one in 3,000-4,000 live births among Caucasians and is even less common in other ethnicities. ${ }^{1,2}$ In Oman, sarcoidosis is not uncommon, with a similar clinical picture to that reported elsewhere; in contrast, the prevalence of CF is estimated to be one in 2,738 individuals. ${ }^{3,4}$ As both conditions are quite rare, the unrelated coexistence of these diseases in a single patient is extremely unlikely. This case report describes the successful response to sarcoidosis treatment in a CF patient who presented with hypercalcaemia, uveitis and mediastinal lymphadenopathy.

\section{Case Report}

A 22-year-old deaf and mute male patient with a long history of bilateral bronchiectasis was admitted to the Sultan Qaboos University Hospital, Muscat, Oman, with septic shock in 2013. Upon admission, his serum calcium levels were noted to be slightly elevated $(2.65 \mathrm{mmol} / \mathrm{L})$; however, they normalised following the administration of fluids. A diagnosis of $\mathrm{CF}$ was confirmed based on a sweat chloride test of $86 \mathrm{mmol} / \mathrm{L}$, faecal elastase level of $<50 \mu \mathrm{g} / \mathrm{L}$ and genetic testing showing a homozygous p.Ser549Arg mutation. Upon discharge, the patient was advised to manage his condition with nutritional and enzyme supplements, proper dietary habits and chest 
Table 1: Laboratory test results of a 22 -year-old male patient with cystic fibrosis

$\begin{array}{lcc}\text { Variable } & \text { Result } & \begin{array}{c}\text { Normal } \\ \text { range* }\end{array} \\ \text { Hb in g/dL } & 12.7 & 11.5-15.5 \\ \text { Platelet count in } \times 10^{9} / \mathrm{L} & 253 & 150-450 \\ \text { WBC count in } \times 10^{\circ} / \mathrm{L} & 6.2 & 2.2-10 \\ \text { INR } & 1.14 & 0.88-1.10 \\ \text { Serum ALT in U/L } & 3.7 & 0-41 \\ \text { Serum albumin in g/L } & 42 & 35-52 \\ \text { Serum CRP in mg/L } & 5 & 0-5 \\ \text { Calcium in mmol/L } & 3.08 & 2.15-2.55 \\ \text { ALP in U/L } & 165 & 40-129 \\ \text { Creatinine in } \mu \text { mol/L } & 134 & 59-104 \\ \text { 24-hour urinary calcium in mmol } & 25.47 & 2.5-8 \\ \text { PTH in pmol/L } & <0.1 & 1.6-9.3 \\ \text { PTHrP in pmol/L } & 0.7 & <1.3 \\ \text { Vitamin A in } \mu \text { mol/L } & 2.67 & 1.72-2.52 \\ \text { Serum 25-OH cholecalciferol in nmol/L } & 29 & 75-250 \\ \text { 1,25-OH vitamin D in pmol/L } & 228 & 48-144 \\ \text { Serum ACE in ACEU } & 116 & 12-68\end{array}$

$H b=$ haemoglobin; $W B C=$ white blood cell; INR = international normalised ratio; $A L T=$ alanine transaminase; $C R P=C$-reactive protein; $A L P=$ alkaline phosphatase; PTH = parathyroid hormone; $P T H r P=P T H$-related peptide; $\mathrm{OH}=$ hydroxy; $A C E=$ angiotensin-converting enzyme. "Age-specific reference ranges.

physiotherapy. Three months later, he was admitted again with septic shock. At this time, he complained of blurred vision and redness of the eyes. An ultrasound scan of the abdomen showed mild hepatosplenomegaly. The patient was diagnosed with bilateral nongranulomatous anterior uveitis and topical treatment was initiated.

Two months later, during a routine follow-up visit, a blood work-up revealed elevated calcium $(3.08 \mathrm{mmol} / \mathrm{L})$, alkaline phosphatase $(165 \mathrm{U} / \mathrm{L})$ and creatinine $(134 \mu \mathrm{mol} / \mathrm{L})$ levels, while all other electrolytes were within normal limits. Upon examination, the patient was asymptomatic and denied any nausea, vomiting, weakness, lethargy or palpitations. His urinary and bowel movements were normal and his blood pressure was 104/60 mmHg. He was mildly dehydrated with a pulse rate of 110 beats/minute. An abdominal examination revealed that the liver was palpable $2 \mathrm{~cm}$ below the right costal margin. Moreover, his 24-hour urinary calcium level was very high $(25.47 \mathrm{mmol})$, while serum parathyroid hormone $(\mathrm{PTH})$ levels were low $(0.01 \mathrm{pmol} / \mathrm{L})$ and $\mathrm{PTH}-$ related peptide levels were normal $(0.7 \mathrm{pmol} / \mathrm{L})$.The patient was also vitamin $\mathrm{D}$-deficient, with a serum 25-hydroxy $(\mathrm{OH})$ cholecalciferol level of $29 \mathrm{nmol} / \mathrm{L}$, despite an elevated 1,25-OH vitamin D level. His serum angiotensin-converting enzyme (ACE) level was 116 ACEU. The results of other basic laboratory tests were normal [Table 1]. Sputum microscopy, cultures and a polymerase chain reaction analysis for mycobacterium tuberculosis were negative. Autoimmune screening was also negative for rheumatoid factor, antinuclear antibodies, cytoplasmic- antineutrophil cytoplasmic antibodies (ANCAs) and perinuclear-ANCAs.

Computed tomography (CT) of the chest showed mediastinal lymphadenopathy, with the largest lymph node in the prevascular region measuring $2.7 \times 1.0 \mathrm{~cm}$, and minimal bilateral bronchiectatic changes [Figure 1]. A few faint irregular nodular opacities in the distal lung were also seen. A CT scan of the abdomen showed multiple lymph nodes, with the largest located in the porta hepatis measuring $2.5 \times 1.4 \mathrm{~cm}$; in addition, complete replacement of the pancreatic tissue by fat was observed, along with hepatosplenomegaly. A mediastinoscopy and lymph node biopsy was scheduled; however, the patient and his family refused the surgery. A bone marrow biopsy showed normal trilineage representation without any abnormalities.

A clinical diagnosis of sarcoidosis was made based on the presence of mediastinal and abdominal lymphadenopathy, anterior uveitis, mild hepatosplenomegaly, non-parathyroid-related hypercalcaemia, calciuria and elevated 1,25-OH vitamin D and ACE levels. The patient was prescribed steroids in the form of oral prednisolone.

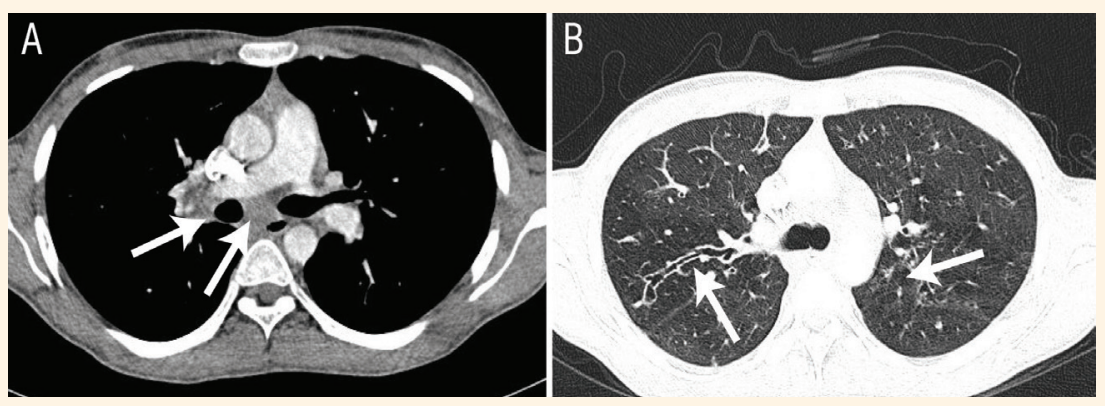

Figure 1: Computed tomography scans of the chest of a 22-year-old male cystic fibrosis patient with asymptomatic hypercalcaemia showing mediastinal lymphadenopathy and bilateral bronchiectatic changes (arrows). 
His serum calcium levels normalised during the first few weeks of treatment and remained normal throughout the follow-up period; however, over the following month, he developed steroid-induced diabetes and required insulin. In addition, he was subsequently admitted twice, a year apart, primarily to optimise his CF treatment and for parenteral antibiotics.

Prednisolone treatment was continued for two years in tapering doses, resulting in the near-complete resolution of the patient's parenchymal nodular infiltrates, regression of hilar lymphadenopathy, resolution of hypercalcaemia and the normalisation of his ACE levels. The insulin was discontinued one month after the patient stopped taking prednisolone.

\section{Discussion}

Worldwide, there are very few reports documenting the coexistence of CF and sarcoidosis; this is possibly because the true incidence of sarcoidosis in $\mathrm{CF}$ is underreported, as such patients already have widespread lung involvement. ${ }^{2}$ The first published cases originated from the UK in 1987, in which Cooper et al. described two children with known $\mathrm{CF}$, one of whom presented with multisystem disease. ${ }^{5}$ Since then, a few reports have been published detailing CF patients presenting with either pulmonary or systemic symptoms of sarcoidosis. ${ }^{6-11}$ However, to the best of the authors' knowledge, the current case is the first in which asymptomatic hypercalcaemia was an early sign of sarcoidosis in a CF patient.

In view of the low prevalence of both conditions, there may be a pathogenic link between CF and sarcoidosis. This may be due to either a common genetic predisposition or an acquired immune response defect. Both sarcoidosis and CF patients demonstrate defective $\mathrm{T}$ cell-mediated immune function and enhanced $\mathrm{B}$ cell activation. ${ }^{5}$ However, CF is caused by a mutation of the cystic fibrosis transmembrane regulator (CFTR) gene located on chromosome 7, while sarcoidosis susceptibility, phenotype and prognosis is associated with many gene variants, including variations in the major histocompatibility complex class II gene subgroup. ${ }^{1,2}$ Nevertheless, although previous research has suggested that there is a high frequency of CFTR mutations in patients with sarcoidosis, the findings of another moderately-sized study did not support an association between CFTR mutations and sarcoidosis phenotype. ${ }^{12,13}$

The altered immune response in CF secondary to chronic infection could also be responsible for the development of sarcoidosis. ${ }^{5}$ Antigen presentation may be potentiated by tissue damage exposing the raw bronchial mucosal surfaces; as a result, sarcoid granulomas could develop in response to immune stimulation by these antigens originating from microorganisms or from glyco- proteins and polypeptides generated by monocytemacrophage hyperactivity. ${ }^{5-7}$ It is worth noting that Mycobacterium, Propionibacterium and various fungi, viruses and spirochetes have also been implicated in the development of sarcoidosis. ${ }^{1}$ As such, further research is necessary to confirm a link between the two conditions and to establish a causative mechanism.

Apart from sarcoidosis, hypervitaminosis A may be another explanation for the hypercalcaemia noted in the current case. Chronic vitamin A toxicity can result from the ingestion of large amounts of vitamin A over a long period, with hypercalcaemia resulting from the direct effect of vitamin A on the bone, parathyroid glands or both. ${ }^{14}$ However, in the present case, the patient had slightly high serum calcium levels prior to his CF diagnosis and recommendations for vitamin A supplementation. At the time, his serum calcium levels would have normalised as a result of the fluids given to manage the shock. Accordingly, a clinical diagnosis of sarcoidosis was made based on the presence of mediastinal and abdominal lymphadenopathy, anterior uveitis, mild hepatosplenomegaly, non-parathyroid-related hypercalcaemia, calciuria and elevated 1,25-OH vitamin D and ACE levels.

\section{Conclusion}

A pathogenic link may exist between sarcoidosis and $\mathrm{CF}$ in terms of a common genetic predisposition or an altered immune response; however, this supposition as yet remains hypothetical and requires further research for confirmation. Regardless, a diagnosis of pulmonary sarcoidosis in CF is challenging as most adult patients already have extensive lung disease. In such cases, hypercalcaemia may be an early sign.

\section{References}

1. Valeyre D, Prasse A, Nunes H, Uzunhan Y, Brillet PY, MüllerQuernheim J. Sarcoidosis. Lancet 2014; 383:1155-67. https://doi.org/ 10.1016/S0140-6736(13)60680-7.

2. Sanders DB, Fink AK. Background and epidemiology. Pediatr Clin North Am 2016; 63:567-84. https://doi.org/10.1016/j.pcl. 2016.04.001.

3. Jayakrishnan B, Al-Busaidi N, Al-Lawati A, George J, Al-Rawas OA, Al-Mahrouqi Y, et al. Clinical features of sarcoidosis in Oman: A report from the Middle East region. Sarcoidosis Vasc Diffuse Lung Dis 2016; 33:201-8.

4. Al-Kindy $\mathrm{H}$, Ouhtit A, Al-Salmi Q, Al-Bimani M, Al-Nabhani M, Gupta I. Novel mutation in the CFTR gene of cystic fibrosis patients in Oman. J Mol Biomark Diagn 2014; 5:168. https://doi.org/10.4172/2155-9929.1000168.

5. Cooper TJ, Day AJ, Weller PH, Geddes DM. Sarcoidosis in two patients with cystic fibrosis: A fortuitous association? Thorax 1987; 42:818-20. https://doi.org/10.1136/thx.42.10.818.

6. Kamarova H, Thattakkat K, McCann L. Cystic fibrosis with sarcoidosis: Genetics vs immunology - A paradigm shift? Arch Dis Child 2010; 95:A36. https://doi.org/10.1136/adc.2010.1863 38.82 . 
7. Dobbin CJ, Moriarty C, Bye PT. Granulomatous diseases in a patient with cystic fibrosis. J Cyst Fibros 2003; 2:35-7. https://doi. org/10.1016/S1569-1993(02)00140-6.

8. Doubková M, Binková I, Skřičková J. [Hidden cystic fibrosis in patient suffering from sarcoidosis]. Vnitr Lek 2012; 58:329-34.

9. Burton CM, Pressler T, Milman N. Pulmonary sarcoidosis in a child with cystic fibrosis. Pediatr Pulmonol 2005; 39:473-7. https://doi.org/10.1002/ppul.20208.

10. Soden M, Tempany E, Bresnihan B. Sarcoid arthropathy in cystic fibrosis. Br J Rheumatol 1989; 28:341-3. https://doi.org/10.109 3/rheumatology/28.4.341.

11. Rettinger SD, Trulock EP, Mackay B, Auerbach HS. Sarcoidosis in an adult with cystic fibrosis. Thorax 1989; 44:829-30. https://doi.org/10.1136/thx.44.10.829.
12. Schürmann M, Albrecht M, Schwinger E, Stuhrmann M. CFTR gene mutations in sarcoidosis. Eur J Hum Genet 2002; 10:729-32. https://doi.org/10.1038/sj.ejhg.5200868.

13. Bombieri C, Luisetti M, Belpinati F, Zuliani E, Beretta A, Baccheschi J, et al. Increased frequency of CFTR gene mutations in sarcoidosis: A case/control association study. Eur J Hum Genet 2000; 8:717-20. https://doi.org/10.1038/sj.ejhg.5200524.

14. Safi KH, Filbrun AG, Nasr SZ. Hypervitaminosis A causing hypercalcemia in cystic fibrosis: Case report and focused review. Ann Am Thorac Soc 2014; 11:1244-7. https://doi.org/10.1513/A nnalsATS.201404-170BC. 